\title{
Pseudopregnancy in a doe and its hormonal therapy
}

\begin{abstract}
A female Saanen goat, weighing about $65 \mathrm{~kg}$ with a body condition score of 3 out of 5 , and a history of distended abdomen and udder enlargement for a prolonged period with no subsequent kidding was visited for pregnancy checkup. Physical examination of the abdomen revealed abdominal distention with presence of fluid felt up on ballottement as well as udder enlargement. Subsequent examination by abdominal ultrasonography confirmed presence of massive clear anechoic uterine fluid with hyperechoic trabeculae, with no other pregnancy features such as placentomes and fetal structures, leading to the final diagnosis of hydrometra / pseudopregnancy. The doe was subsequently treated with IM injections of 2 doses of synthetic prostaglandin PGF2ï $i$ - Estrumate ${ }^{\circledR}$ which contains $250 \mu \mathrm{g} / \mathrm{ml}$ of cloprostenol at 12 days interval that effectively resolved the problem based on physical and sonographic evidences during a follow up visit. Early detection and hormonal therapy of pseudopregnancy in dairy goats could help to prevent economic loss from keeping the doe without reproduction.
\end{abstract}

Keyword: Pseudopregnancy; Doe; Uterine fluid; Ultrasound; Cloprostenol 